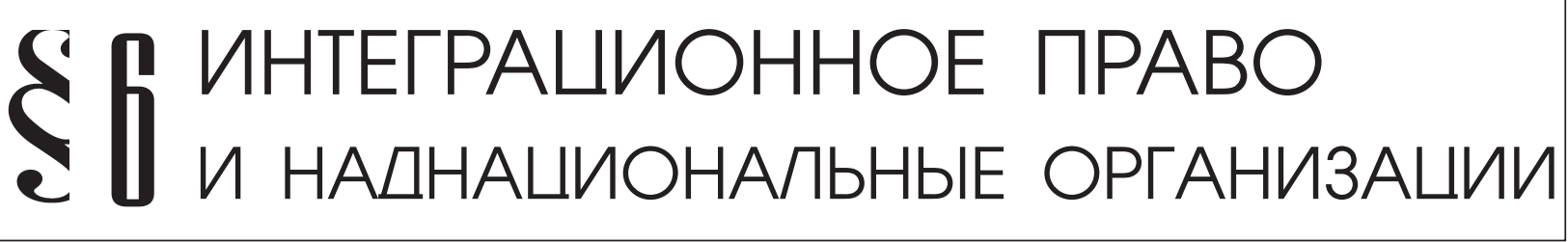

Можуга В.В

\section{ПРОБЛЕМЫ ПРАВОВОГО РЕГУЛИРОВАНИЯ ЗАЩИТЫ ОБЪЕКТОВ ИНТЕЛЛЕКТУАЛЬНОЙ СОБСТВЕННОСТИ ТАМОЖЕННЫМИ ОРГАНАМИ ГОСУДАРСТВ-ЧЛЕНОВ ТАМОЖЕННОГО СОЮЗА}

\begin{abstract}
Аннотация: Предметом исследования выступают правовые основы защиты таможенными органами Таможенного союза объектов интеллектуальной собственности. Разбирается проблема соотношения международного и национального законодательства стран по вопросам перемещения товаров, содержащих результаты интеллектуальной деятельности. Сравнивается порядок применения мер по защите объектов интеллектуальной собственности в рамках реестровых поставок, при контроле по ех оfficio и при осуществлении проверочных мероприятий после выпуска товаров. Анализируется административное законодательство трех стран по вопросам сроков истечения исковой давности за таможенные правонарушения. В качестве основного метода работы используется метод сравнительного правоведения, используемый при сопоставлении положений законодательства стран-участнии Таможенного союза по вопросам зашиты объектов интеллектуальной собственности. Большая часть норм, регулирующих защиту объектов интеллектуальной собственности таможенными органами, содержится в национальном законодательстве стран-членов Таможенного союза. Представляется необходимым унифицировать законодательство в сфере привлечения к административной ответственности за нарушение прав на объекты интеллектуальной собственности, вывести его на наднациональный уровень и установить трехлетний срок давности по данной категории дел.Кроме того, на требует закрепления на наднациональном уровне вопрос защиты, объектов интеллектуальной собственности, не включенных в реестр в рамках ех оfficio.
\end{abstract}

Ключевые слова: Таможенный союз, интеллектульная собственность, ех оfficio, Всемирная торговая организация, таможенные органы, защита интеллектуальной собственности, контроль после выпуска, охрана интеллектуальной собственности, Таможенный кодекс, унификация административного законодательства.

Abstract: The subject of this research is the legal grounds of protection of the objects of intellectual property by the Customs Union agencies. The author examines the problem of correlation between the international and national legislation of the countries regarding the questions of transfer of the goods containing the results of intellectual property. The work compares the order of implementation of measures on protection of the intellectual property objects within the framework of the registry deliveries control by ex officio, as well as realization of verification measures after the release of goods. The author analyzes the administrative legislation of three countries pertaining to the questions of expiration of statute of limitations for customs law violation. The method of comparative jurisprudence is implemented for analyzing the positions of legislation of the Customs Union member-states regarding the questions of protection of the intellectual property objects. Majority of the norms, which regulate that protection of the intellectual property objects by the customs agencies, is contained in the national legislation of the Customs Union member-states. The author believes that there is a need to unify legislation in the area of administrative accountability for violation of rights upon the objects of intellectual property, introduce it at the supranational level, as well as set a three-year term of limitations on this matter.

Keywords: Unification of administrative legislation, Customs Code, Protection of intellectual property, Control after the release, Customs Union member-states, Customs agencies, World Trade Organization, Ex officio, Intellectual property, Customs Union. 
B современном мире защита интеллектуальной собственности - вопрос первостепенной важности, вышедший за пределы ведения отдельных стран и регулируемый целым массивом международных соглашений, как в рамках международных организаций, так и в рамках интегративных объединений.

Согласно Таможенному кодексу Таможенного союза ${ }^{1}$ одной из функций таможенных органов является обеспечение защиты прав объектов интеллектуальной собственности на таможенной территории Таможенного союза, а также контроль за правильностью определения таможенной стоимости товара и взимания таможенных платежей. Поэтому при пересечении товарами таможенной границы Таможенного союза особое значение приобретают два аспекта:

- $\quad$ включение платежей за использование объектов интеллектуальной собственности в таможенную стоимость товаров,

- $\quad$ соблюдение мер по защите прав интеллектуальной собственности.

Прежде всего, необходимо акцентировать внимание на том, что при осуществлении внешней торговли объекты интеллектуальной собственности редко выступают непосредственными объектами правоотношений и рассматриваются в контексте перемещаемых через таможенную границу товаров. Товары, содержащие объекты интеллектуальной собственности - это материальные носители, включающие в себя результаты интеллектуальной деятельности, выступающие в качестве объекта внешнеэкономической сделки. В рамках регулирования внешнеэкономической деятельности государственные органы осуществляют контроль именно за товарами, содержащими объекты интеллектуальной собственности, минуя вопросы самой интеллектуальной деятельности в отрыве от коммерческой деятельности. В этой связи необходимо разграничивать два связанных между собой, но не идентичных понятия «охрана прав на объекты интеллектуальной собственности» и «защита прав на объекты интеллектуальной собственности».

Охрана прав на объекты интеллектуальной собственности - комплекс мер профилактического и превентивного характера, направленных на предотвращение нарушения прав на объекты интеллектуальной собственности. Охрана прав на объекты

\footnotetext{
1 Таможенный Кодекс Таможенного союза (Приложение к Договору о Таможенном Кодексе таможенного союза, принятому решением ЕвразЭС от 27 ноября 2009 года №17 (в ред. Протокола от 16 апреля 2010 года) [Электронный ресурс] // Справочно-правовая система «Консультант Плюс». - Режим доступа: http://base. consultant.ru/cons/cgi/online.cgi?req $=$ doc;base $=\mathrm{LAW} ; \mathrm{n}=100808$.
}

интеллектуальной собственности носит пассивный декларативный характер и выражается в законодательном закреплении возможности осуществлять защиту своих прав и установлению комплекса инструментов по правомерной защите.

Защита прав на объекты интеллектуальной собственности - активные меры по восстановлению нарушенного права на объекты интеллектуальной собственности, а также меры по пресечению непосредственного посягательства на это право и мероприятия, связанные с ликвидацией последствий данного противоправного деяния.

Таможенные органы, как и иные правоохранительные органы, обладают рядом полномочий по защите объектов интеллектуальной собственности. В то же время эффективность деятельности таможенных органов Российской Федерации по защите прав интеллектуальной собственности зависит от качества нормативно-правовой базы, регулирующей их компетенцию в данной сфере. Создание Единого экономического пространства в рамках Таможенного союза породило целый массив нормативно-правовых актов, связанных с защитой объектов интеллектуальной собственности как на наднациональном, так и на национальном уровне и, чтобы стать реально действующим инструментом защиты интеллектуальной собственности, таможенное законодательство Таможенного союза по вопросам защиты интеллектуальной собственности активно унифицируется и выводится на наднациональный уровень.

Ключевым документом, регламентирующим вопросы интеллектуальной собственности в Таможенном союзе, выступает Таможенный Кодекс Таможенного союза, определяющий задачи таможенных органов и меры по защите прав на объекты интеллектуальной собственности (ОИС), принимаемые таможенными органами. Положения Кодекса раскрываются и конкретизируются в национальном законодательстве и соглашениях в рамках Союза, в частности Соглашении «О единых принципах регулирования в сфере охраны и защиты прав интеллектуальной собственности»².

Соглашение предусматривает унификацию вопросов охраны и защиты интеллектуальной собственности в рамках Единого экономического пространства и направлено на создание равных условий доступа товаров, содержащих объекты интеллектуальной собственности на рынки государств-участников Соглашения.

\footnotetext{
${ }^{2}$ Соглашение от 09.12.2010 «О единых принципах регулирования в сфере охраны и защиты прав интеллектуальной собственности» // Собрание законодательства РФ. 30.01.2012. № 5. Ст. 542.
} 


\section{Право и политика $11(203) \cdot 2016$}

Особенностью Соглашения является то, что оно устанавливает приоритет соглашений Всемирной организации интеллектуальной собственности и ВТО и создание постоянно действующего институционального механизма по информационно-техническому сотрудничеству в области охраны и защиты интеллектуальной собственности - Координационного совета Единого экономического пространства по интеллектуальной собственности.

В целом существенных расхождений между национальным законодательством трех стран и Соглашением нет, в то же время часть международных договоров, на которые ссылается Соглашение о единых принципах регулирования в сфере охраны и защиты прав интеллектуальной собственности, не ратифицированы той или иной страной-членом Таможенного союза (в частности от Республики Беларусь потребуется присоединение к Сингапурскому договору о законах по товарным знакам 2007 года и Договору о патентном праве 2000 года, а от Казахстана также к международной конвенции об охране прав исполнителей, изготовителей фонограмм и вещательных организаций 1961 года).

Кроме того, ст. 2 Соглашения предусматривает необходимость присоединения стран к ВТО с последующим координированием действий в рамках Комитета по Соглашению о торговых аспектах прав интеллектуальной собственности Всемирной торговой организации. В то же время Республика Казахстан и Республика Беларусь еще находятся в статусе наблюдателей ВТО.

Одним из основополагающих моментов соглашения является обязанность по заключению договора, предусматривающего создание единых процедур, необходимых для обеспечения правовой охраны товарных знаков и наименований мест происхождения товаров (географических указаний) на территории государств-членов Таможенного союза, а также единых механизмов регистрации товарных знаков и наименований мест происхождения товаров. В настоящее время принятие данного соглашения находится на стадии согласования позиций. В то же время проект Соглашения предусматривает крайне важный для таможенных органов принцип исчерпания исключительных прав на товарный знак в рамках единого экономического пространства (ЕЭП) - не является нарушением исключительного права на товарный знак ЕЭП использование этого товарного знака ЕЭП в отношении товаров, которые были правомерно введены в гражданский оборот на территории государствчленов ТС непосредственно правообладателем или другими лицами с его согласия (расширив в странах-участницах Соглашения исчерпание права с национального до регионального уровня).

Возвращаясь к Таможенному кодексу Таможенного союза, следует отметить, что ст. 328 Таможенного кодекса Таможенного союза устанавливает новую для России возможность защиты объектов интеллектуальной собственности ех officio, в соответствии с законодательством государств-членов Таможенного союза 3 . Т.е. у таможенных органов появляется полномочие приостановить выпуск товаров, содержащих объекты интеллектуальной собственности, не внесенных в таможенный реестр ОИС при обнаружении признаков нарушения прав интеллектуальной собственности и при наличии информации о правообладателе (его представителе). В то же время, данное полномочие устанавливается только на национальном уровне, что порождает различия в правоприменении. Так, в Российской Федерации этот вопрос регулируется ст. 308 Ф3 «О таможенном регулировании» ${ }^{4}$, в Республике Казахстан ст. 441 Кодекса республики Казахстан «О таможенном деле в республике Казахстан» республике Беларусь не предусмотрен в принципе. При этом порядок и сроки применения мер по защите интеллектуальной собственности в рамках ех officio в России и Казахстане существенно отличаются. Например, если в России срок приостановления выпуска товаров составляет 7 рабочих дней, то в Казахстане он равен всего 3 рабочим дням. С учетом того, что с 1 июля 2011 года полностью снят таможенный контроль на территории Таможенного союза, и, соответственно, исключается участие таможенных органов в контроле за соблюдением прав интеллектуальной собственности при ввозе в Российскую Федерацию товаров, выпущенных в оборот на территории Республики Беларусь и Республики Казахстан, установление единых мер по защите интеллектуальной собственности представляется крайне важным.

\footnotetext{
3 Таможенный кодекс Таможенного союза (приложение к Договору о Таможенном кодексе Таможенного союза, принятому Решением Межгосударственного Совета ЕврАзЭС на уровне глав государств от 27.11.2009 № 17) // Собрание законодательства РФ. 13.12.2010. № 50. Ст. 6615.

${ }^{4}$ Федеральный закон от 27.11.2010 № 311-Ф3 «О таможенном регулировании в Российской Федерации» // Собрание законодательства РФ. 29.11.2010. № 48. Ст. 6252.

${ }^{5}$ Кодекс Республики Казахстан от 30 июня 2010 года № 296-IV «O таможенном деле в Республике Казахстан» (Таможенный кодекс) (с изменениями и дополнениями по состоянию на 04.07.2013 г.) // Казахстанская правда. 02.07.2010. № 169-170 (26230-26231).
} 
Сравнивая особенности применения ех officio в России и Казахстане можно выделить следующие различия:

1. Основаниями применения мер по ех officio в России выступает обнаружение признаков нарушения прав интеллектуальной собственности, а также наличие информации о правообладателе (его представителе) на территории Российской Федерации. В то время как в соответствии с Кодексом Республики Казахстан «О таможенном деле в Республике Казахстан» для защиты по ех officio не требуется наличие информации о правообладателе.

2. В России уведомление правообладателя о приостановлении выпуска должно осуществляться не позднее следующего дня после приостановления выпуска товаров, тогда как Кодекс Республики Казахстан оперирует более размытым понятием «незамедлительно», предоставляя таможенному органу время на определение места нахождения правообладателя.

3. Срок приостановления выпуска по еx officio в России составляет 7 рабочих дней с возможностью продления еще на 10 рабочих дней, тогда как в Республике Казахстан этот срок составляет 3 рабочих дня с аналогичной возможностью продления.

4. Закон «О таможенном регулировании в Российской Федерации» в качестве дополнительного условия продления срока приостановления выпуска устанавливает необходимость подачи заявления о включении соответствующего объекта интеллектуальной собственности в реестр объектов интеллектуальной собственности.

Ее одной правовой проблемой нормативноправового регулирования защиты интеллектуальной собственности таможенными органами является постконтроль. Федеральная таможенная служба определила контроль после выпуска товаров, в качестве одного из стратегических направлений деятельности таможенных органов. Такое решение объясняется необходимостью достижения баланса между упрощением таможенных процедур (увеличение доли постконтрольных мероприятий соответствует общемировой практике и принципам Киотской конвенции) и противодействием правонарушений области таможенного дела.

В настоящее время правовое регулирование таможенного контроля после выпуска товаров сосредоточено в подзаконных актах, таких как приказы ФТС от 06 июля 2012 г. № 1373 «Об утверждении Инструкции о действиях должностных лиц таможенных органов при проведении таможенного контроля в форме таможенной проверки» и от 06 июля 2012 г. № 1372 «Об утверждении Инструкции о действиях должностных лиц таможенных органов при взаимодействии подразделений таможенного контроля после выпуска товаров и структурных подразделений таможенных органов при организации таможенного контроля после выпуска товаров». В этой связи возникает две основные проблемы.

Таможенный кодекс Таможенного союза в качестве ключевой меры по защите прав на объекты интеллектуальной собственности установил приостановление выпуска товаров. При постконтроле данная мера, очевидно, не применима.

В то же время таможенные органы правомочны проводить таможенный контроль после выпуска товаров в течение трех лет, тогда как срок давности привлечения к административной ответственности по статьям 7.12 и 14.10 КоАП РФ составляет два года ${ }^{6}$ (в Республике Беларусь 3 года7 ${ }^{7}$ в республике Казахстан -5 лет $^{8}$, но данная категория дел не относится к ведению таможенных органов и не подпадает под правонарушения в сфере таможенного дела).

А так как в соответствии с п. 15 Постановления Пленума ВАС РФ от 17.02.2011 № 11 «О некоторых вопросах применения Особенной части Кодекса Российской Федерации об административных правонарушениях» ${ }^{9}$ данные административные правонарушения считаются оконченным в день выпуска товара в соответствии с заявленной таможенной процедурой, прослеживается явное несоответствие сроков давности и сроков проведения таможенной проверки.

Представляется необходимым унифицировать законодательство в сфере привлечения к административной ответственности за нарушение прав на объекты интеллектуальной собственности, вывести его на наднациональный уровень и установить трехлетний срок давности по данной категории дел.

В заключение следует отметить, что большая часть норм, регулирующих защиту объектов интел-

${ }^{6}$ Кодекс Российской Федерации об административных правонарушениях от 30.12.2001 № 195-Ф3 // Собрание законодательства РФ. 07.01.2002. № 1 (ч. 1). СТ. 1.

${ }^{7}$ Кодекс Республики Казахстан об административных правонарушениях от 30 января 2001 года № 155-II (с изменениями и дополнениями по состоянию на 04.07.2013 г.) // Казахстанская правда от 13.02.2001. № 40-41 (23388-23389).

${ }^{8}$ Кодекс Республики Беларусь об административных правонарушениях от 21 апреля 2003 года № 194-3 // Национальный реестр правовых актов Республики Беларусь. 09 .06.2003. № 63, 2/946.

${ }^{9}$ Постановление Пленума ВАС РФ от 17.02.2011 № 11 «О некоторых вопросах применения Особенной части Кодекса Российской Федерации об административных правонарушениях» // Вестник ВАС РФ. № 5, май, 2011. 
DOI: $10.7256 / 1811-9018.2016 .11 .12559$

При цитировании этой статьи сноска на doi обязательна

Право и политика $11(203) \cdot 2016$

лектуальной собственности таможенными органами, содержится в национальном законодательстве странчленов Таможенного союза, что не соответствует ни мировым тенденциям, ни интересам государств.
Таким образом, целесообразным было бы все вопросы защиты объектов интеллектуальной собственности вынести на уровень совместного регулирования в рамках Таможенного союза.

\section{Библиография:}

1. Павлов П.В.. Оценка эффективности функционирования особых экономических зон: правовое регулирование и экономическое содержание // Административное и муниципальное право. - 2014. - № 6. - С. 104-107. DOI: 10.7256/19992807.2014.6.12108

2. Можуга В.В. Факторы, влияющие на иерархическую зависимость источников публичного права в Таможенном союзе // NB: Международное право. — 2013. - № 4. - C.1-15. DOI: 10.7256/2306-9899.2013.4.10104. URL: http://e-notabene.ru/ wl/article 10104.html

3. Мошкина Н.А. Правовая природа досмотра как формы контроля: административный и таможенный аспект // NB: Административное право и практика администрирования. — 2013. - № 3. - C.1-24. DOI: 10.7256/2306-9945.2013.3.655. URL: http://e-notabene.ru/al/article $655 . h t m l$

4. Васильев Р.И. Правовое регулирование контроля таможенной стоимости // NB: Административное право и практика администрирования. — 2013. - № 1. - C.63-128. DOI: 10.7256/2306-9945.2013.1.582. URL: http://e-notabene.ru/al/ article_582.html

5. Агамагомедова С.А. Таможенный постконтроль в отношении товаров, содержащих объекты интеллектуальной собственности // NB: Административное право и практика администрирования. — 2013. - № 2. - C.105-121. DOI: 10.7256/2306-9945.2013.2.625. URL: http://e-notabene.ru/al/article_625.html

6. Мошкина Н.А. Реализация интересов государств в условиях интеграции (на примере таможенного союза России, Белоруссии и Казахстана) // NB: Международные отношения. — 2012. - № 1. - C.80-91. DOI: 10.7256/2306-4226.2012.1.32. URL: http://e-notabene.ru/wi/article_32.html

7. Гараев А.А.. Удержание таможенных пошлин, налогов с сумм, полученных от реализации товаров, задержанных таможенными органами // Налоги и налогообложение. - 2014. - № 3. - C. 104-107. DOI: 10.7256/1812-8688.2014.3.11386

8. О. В. Маркова Перспективы правовой защиты интеллектуальной собственности и способы укрепления устойчивого элемента системы правовой защиты интеллектуальной собственности // Политика и Общество. - 2012. - 6. - С. 101-106.

9. Агамагомедова С.А. Порядок действий таможенных органов РФ по защите прав на объекты интеллектуальной собственности и его оптимизация в современных условиях // Административное и муниципальное право. - 2014. - 6. - C. 559-568. DOI: 10.7256/1999-2807.2014.6.10860.

10. Кобзарь-Фролова М.Н.. Административно-правовое регулирование экономической деятельности таможенных органов // Административное и муниципальное право. - 2013. - № 12. - С. 104-107. DOI: 10.7256/1999-2807.2013.12.9853

11. Ким Н.И.. О практике назначения административного штрафа за правонарушения в области таможенного дела // Административное и муниципальное право. - 2013. - № 12. - C. 104-107. DOI: 10.7256/1999-2807.2013.12.1023

12. Владимирова Т.В. Проблема устойчивости порядка как угроза безопасности // NB: Национальная безопасность. 2013. - 2. - C. 67 - 87. DOI: 10.7256/2306-0417.2013.2.590. URL: http://www.e-notabene.ru/nb/article 590.html

\section{References (transliterated):}

1. Pavlov P.V.. Otsenka effektivnosti funktsionirovaniya osobykh ekonomicheskikh zon: pravovoe regulirovanie i ekonomicheskoe soderzhanie // Administrativnoe i munitsipal'noe pravo. - 2014. - № 6. - S. 104-107. DOI: 10.7256/1999-2807.2014.6.12108

2. Mozhuga V.V. Faktory, vliyayushchie na ierarkhicheskuyu zavisimost' istochnikov publichnogo prava v Tamozhennom soyuze // NB: Mezhdunarodnoe pravo. — 2013. - № 4. - S.1-15. DOI: 10.7256/2306-9899.2013.4.10104. URL: http://e-notabene.ru/ wl/article_10104.html

3. Moshkina N.A. Pravovaya priroda dosmotra kak formy kontrolya: administrativnyi i tamozhennyi aspekt // NB: Administrativnoe pravo i praktika administrirovaniya. — 2013. - № 3. - S.1-24. DOI: 10.7256/2306-9945.2013.3.655. URL: http://e-notabene.ru/al/article $655 . h t m l$

4. Vasil'ev R.I. Pravovoe regulirovanie kontrolya tamozhennoi stoimosti // NB: Administrativnoe pravo i praktika administrirovaniya. — 2013. - № 1. - S.63-128. DOI: 10.7256/2306-9945.2013.1.582. URL: http://e-notabene.ru/al/article_582.html

5. Agamagomedova S.A. Tamozhennyi postkontrol' v otnoshenii tovarov, soderzhashchikh ob"'ekty intellektual'noi sobstvennosti // NB: Administrativnoe pravo i praktika administrirovaniya. — 2013. - № 2. - S.105-121. DOI: 10.7256/2306-9945.2013.2.625. URL: http://e-notabene.ru/al/article_625.html

6. Moshkina N.A. Realizatsiya interesov gosudarstv v usloviyakh integratsii (na primere tamozhennogo soyuza Rossii, Belorussii i Kazakhstana) // NB: Mezhdunarodnye otnosheniya. - 2012. - № 1. - S.80-91. DOI: 10.7256/2306-4226.2012.1.32. URL: http://e-notabene.ru/wi/article 32.html

7. Garaev A.A.. Uderzhanie tamozhennykh poshlin, nalogov s summ, poluchennykh ot realizatsii tovarov, zaderzhannykh tamozhennymi organami // Nalogi i nalogooblozhenie. - 2014. - № 3. - S. 104-107. DOI: 10.7256/18128688.2014.3.11386 
DOI: $10.7256 / 1811-9018.2016 .11 .12559$

При цитировании этой статьи сноска на dоі обязательна

Интеграционное право и наднациональные организации

8. O. V. Markova Perspektivy pravovoi zashchity intellektual'noi sobstvennosti i sposoby ukrepleniya ustoichivogo elementa sistemy pravovoi zashchity intellektual'noi sobstvennosti // Politika i Obshchestvo. - 2012. - 6. - C. 101-106.

9. Agamagomedova S.A. Poryadok deistvii tamozhennykh organov RF po zashchite prav na ob"ekty intellektual'noi sobstvennosti i ego optimizatsiya v sovremennykh usloviyakh // Administrativnoe i munitsipal'noe pravo. - 2014. - 6. - C. 559-568. DOI: 10.7256/1999-2807.2014.6.10860.

10. Kobzar'-Frolova M.N.. Administrativno-pravovoe regulirovanie ekonomicheskoi deyatel'nosti tamozhennykh organov // Administrativnoe i munitsipal'noe pravo. - 2013. - № 12. - S. 104-107. DOI: 10.7256/1999-2807.2013.12.9853

11. Kim N.I.. O praktike naznacheniya administrativnogo shtrafa za pravonarusheniya v oblasti tamozhennogo dela // Administrativnoe i munitsipal'noe pravo. - 2013. - № 12. - S. 104-107. DOI: 10.7256/1999-2807.2013.12.1023

12. Vladimirova T.V. Problema ustoichivosti poryadka kak ugroza bezopasnosti // NB: Natsional'naya bezopasnost'. - 2013. - 2. - C. 67 - 87. DOI: 10.7256/2306-0417.2013.2.590. URL: http://www.e-notabene.ru/nb/article_590.html 